\title{
Cost of Hemodialysis in a Tertiary Care Hospital in North India
}

\author{
Mushtaq A, M.B., ' Ajaz Mustafa, M.D., ${ }^{2}$ M. Saleem Najar, M.D.,' Jan Farooq A, M.D., \\ Manhas Anil, M.D., ', Abdul Hakim, M.B., 'Wani Ashraf, M.B., ' Jalali Suzan, M.B.' \\ 'Department of Hospital Administration and ²Nephrology, Sher-i-Kashmir Institute of Medical Sciences, Srinagar, 190011
}

\section{A B S T R A C T}

BACKGROUND: Chronic kidney disease (CKD) is a world wide public health problem with significant health consequences and involvement of high cost on treatment world wide. Although renal transplant is a cost effective treatment option for ESRD, use of hemodialysis in patients with ESRD patients remains one of the most resource intensive and expensive therapeutic intervention.

OBJECTIVE: To estimate cost of hemodialysis treatment for patients with ESRD that would help in making policy decisions and enable cost efficient utilization of ESRD programme and hemodialysis.

METHODS: 58 patients with ESRD on chronic hemodialysis were incorporated in the present study at a tertiary care teaching hospital between January 2010 to December 2010. Patients who survived less than 3 months after commencement of treatment were excluded.

RESULTS: Mean age of the study patients was $46.4 \pm 8$ in yrs. Among the 54 patients studied $51 \%$ were male. $86 \%$ of patients received three sessions of hemodialysis weekly, with duration per session varying between 2 - 4 hours. Average cost was Rs. 2001.84 per session. Estimated total annual burden was Rs. 209449.10 per patient. Average cost borne by hospital was Rs. 951.84 per session/patient (47.55\% of cost bone by the patient); cost born by hospital per patient peryear was Rs. 123647.70.

Principal expenses (\% wise) were: staff salary cost $20.84 \%$, instrument cost (purchased locally from market) $32.50 \%$, salary cost $20.84 \%$, and rental cost $18.20 \%$.

CONCLUSION: The costs estimated in this study comparable with national average cost of hemodialysis in India but lower as compared to that in other SARC countries; a pproaches to reduce cost further are needed. JMS 2012;15(1):47-50.

Key Words: Fixed cost, variable cost, hemodialysis, cost centers, depreciation, cost per session

Chronic kidney disease (CKD) is a world wide public health problem with significant health consequences and involves high cost of treatment world wide. CKD patients often delay treatment due to lack of noticeable symptoms associated with renal disease as well as ignoring these symptoms. This usually results in decline of kidney function which

\section{Correspondence:}

Dr. Ajaz Mustafa

Associate Professor Hospital Administration \& Dy. Med. Supdt.

Sher-i-Kashmir Institute of Medical Sciences,

Srinagar-190011, J \& K, India

E-Mail:dramustafa07@yahoo.co.in ultimately leads to End Stage Renal Disease (ESRD). ${ }^{1}$ Although Renal transplant is a cost effective treatment option for ESRD, ${ }^{2}$ use of Hemodialysis in patients with ESRD remains one of the most resource intensive but expensive therapeutic intervention in India. ${ }^{3}$ Shortage of kidneys transplantation and the increase in demand for RRT will have to be met by dialysis. Of the dialysis modalities currently in use HD places a higher demand especially trained staff. Dialysis has been found reasonably effective at sustaining life in the majority of patients with ESRD. ${ }^{3}$ Patients with ESRD must rely on dialysis for the remainder of their lives unless they undergo kidney transplantation. Additionally growing number 
of ESRD patients will devour a greater proportion of health care budget. The present study is aimed at determining the cost per session of hemodialysis and annual economic burden of hemodialysis on patient and Hospital. An accurate estimate of cost of Hemodialysis treatment for patients with ESRD would help in making policy decisions and enable cost efficient utilization of ESRD programme (HD), most common treatment modality.

\section{Methodology}

A prospective study at Hemodialysis Centre of a tertiary care Teaching Hospital (Sher-i-Kashmir Institute of Medical Sciences, Srinagar, India) was conducted between January 2010 to December 2010. Patients with ESRD and who underwent hemodialysis, were incorporated in the study. Patients who survived less than 3 months after commencement of treatment were excluded. Relevant data was collected by using a predesigned proforma and semi structured interview of the patients and staff at hemodialysis centre was conducted. Case records and electronic data base of hospital were also examined for supplementing the data.

The variables recorded for cost analysis were:- (Direct and Indirect costs)

Cost of Laboratory investigations

Cost of instruments purchased locally from market

Cost of Drugs purchased from market

Cost of diet

Staff salaries (Physician, technologist etc.)

Average variable cost was calculated as total variable cost divided by total number of dialysis sessions during the year of study.

Non medical Supply cost calculated were:-

Electricity cost, cost of water, sanitation cost, Linen \& Laundry, building cost after depreciation plus maintenance and equipment capital cost after depreciation plus maintenance.

Data was scientifically organized and statistically analyzed to identify major cost centres and important variables determining cost of services. A descriptive statistical method to describe demographic variables and disease factors was used. A linear regression model was used to examine the effects of risk factors on variable costs for dialysis patients.

\section{Results}

58 patients were incorporated in the present study. Mean age of the study patients was $46.4+8$ in years. Among the 58 patients studied $51 \%$ were male. Two patients expired during study and two patients were lost to follow up. Eighty six percent $(n=50)$ of patients received three sessions of HD weekly with duration per session varying between two to four hours (average 3 hours ). The breakdown of costs incurred are shown in table 1 as under :-

\section{Discussion}

The exact cost of RRT in developing countries is hard to estimate and varies with the prescription and the way a unit is set up. The overall treatment cost although less in developed countries because of lower staff salaries and the low cost of drugs is still 10-20 times higher than the per capita gross national product and remains out of reach of most of the Hemodialysis population.

As per December 2007 index Rajya Sabah , per capita income in India was 20734 per annum $26 \%$ of total population live below poverty line with daily earning Rs 20/-only. Government spends barely US \# 8 per capita on health.(1)

Chronic kidney disease (CKD) is a world wide public health problem. Although Renal transplant is a cost effective treatment option for ESRD, use of Hemodialysis in patients with ESRD remains one of the most resource intensive and hence expensive therapeutic intervention in India. India has 950 nephrologists 700 dialysis centers, 4000 dialysis machines and 20,000 patients undergoing dialysis at these centers. ${ }^{1}$ These centers are owned predominantly by private sector and are hence concentrated in cities. Government hospitals admit patients on the basis of severity of disease and hence patients on maintenance dialysis are forced to visit to private hospitals.

Cost of each Hemodialysis session in India varies from RS 150/- in Government hospitals to Rs 2000/- in some corporate hospitals. ${ }^{1}$ Average national cost of each session of hemodialysis in India is Rs. 1,100/-..' Monthly cost averages to

Table 1. Showing breakup of cost incurred per session of Hemodialysis

\begin{tabular}{|c|c|c|c|}
\hline Item & $\begin{array}{l}\text { Cost per } \\
\text { session in Rs. }\end{array}$ & $\begin{array}{l}\text { Total } \\
\text { Annual cost }\end{array}$ & $\begin{array}{l}\% \text { of total } \\
\text { cost }\end{array}$ \\
\hline Cost of lab investigations & 90.00 & 11700.00 & 4.50 \\
\hline Cost of instruments purchased & 650.00 & 33800.00 & 32.50 \\
\hline Cost of drugs purchased & 250.00 & 32500.00 & 12.50 \\
\hline Cost of disposables & 15.00 & 1950.00 & 0.75 \\
\hline Staff salaries physician, technologist & 416.68 & 54080.00 & 20.84 \\
\hline Cost of hemodialyzer & 150.00 & 19500.00 & 7.5 \\
\hline Total & 1571.68 & 153530.00 & \\
\hline \multicolumn{4}{|l|}{ Non Medical Supply Cost } \\
\hline $\begin{array}{l}\text { Building cost after depreciation @ } \\
\text { 1\% of capital cost annually 920/sqft } \\
\text { (civil engg records SKIMS) }\end{array}$ & 364.10 & 47330.30 & 18.20 \\
\hline $\begin{array}{l}\text { Maintenance cost @ 15/sq feet } \\
\text { (CPWD memo) }\end{array}$ & 6.0 & 780.0 & 0.35 \\
\hline $\begin{array}{l}\text { Cost of equipment after depreciation } \\
\text { @10\% of capital cost annually }\end{array}$ & 52.20 & 6786.00 & 2.6 \\
\hline Maintenance cost @ 5 \% & 3.08 & 400.40 & 0.15 \\
\hline $\begin{array}{l}\text { Electricity 750/- per kilowatt, } \\
\text { Water @ } 120 \text { liters per session }\end{array}$ & 1.08 & 140.40 & 0.05 \\
\hline Rs 5.50 per tape & 1.0 & 130.0 & 0.05 \\
\hline Sanitation, linen and laundry cost & 2.70 & 351.00 & 0.15 \\
\hline Total & $\begin{array}{l}430.16 \\
2001.84 \\
\end{array}$ & $\begin{array}{l}55918.10 \\
209449.10\end{array}$ & \\
\hline
\end{tabular}


Table 2. Cost borne by Hospital

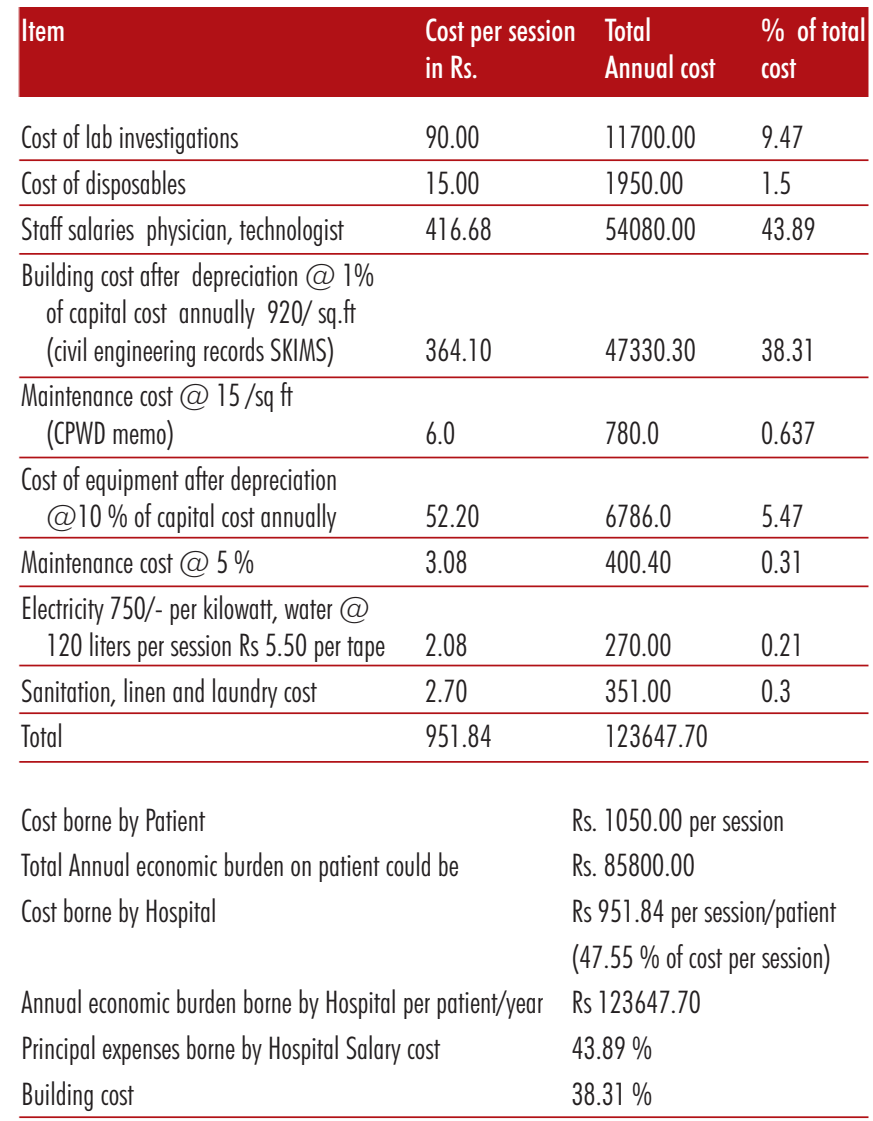

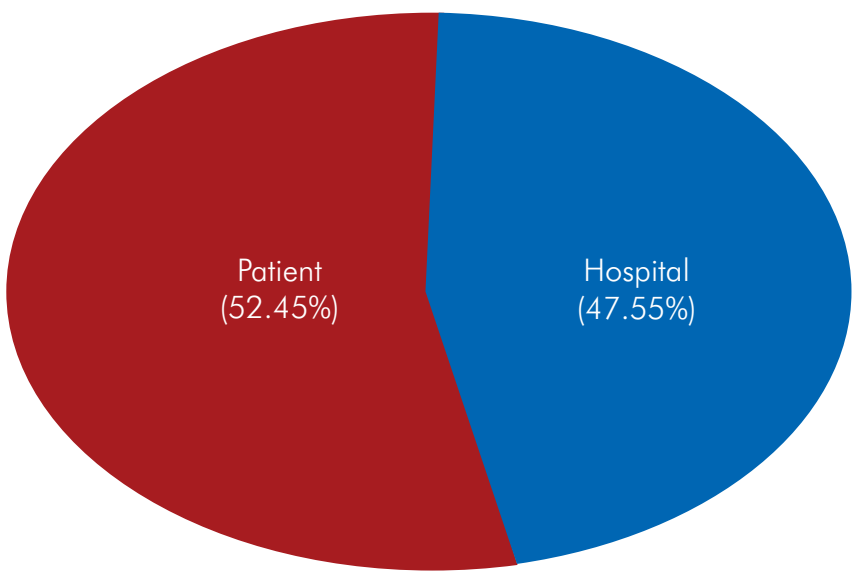

FIGURE 1: Percentage cost borne by Hospital and patient per session

Rs. 12,000/-and yearly Rs, 1,40,000/-. This is cheapest in world yet more than $90 \%$ of the Indians cannot afford it. As $26 \%$ population live below poverty line where daily earnings is Rs. 20/-. ${ }^{1}$

The results of our study reveal that cost of hemodialysis per session is Rs. 2,001.84 amounting to annual burden of Rs. 2,09,449.10 approximately. Cost of hemodialysis in Kashmir is higher than average cost in other states of India (Rs. 1100/-per session) but lower than other SAARC countries. The reason

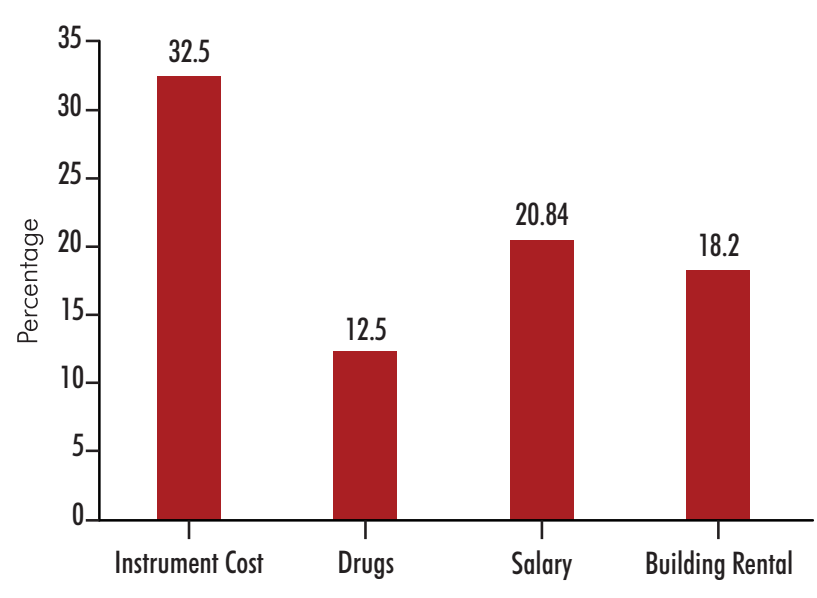

FIGURE 2: Percentage of principal cost Per session of hemodialysis

Table 3. Risk factors associated with increased cost of Hemodialysis

\begin{tabular}{llcc}
\hline \multirow{2}{*}{ Gender } & Number & Percentage \\
& Male & 30 & $51.71 \%$ \\
& Female & 28 & 48.27 \\
\hline Disease & Hypertension & 23 & 42.6 \\
& High lipid Levels & 18 & 33.3 \\
& Cardiovascular Disease & 12 & 22.2 \\
& Diabetes Mellitus & 36 & 66.7 \\
& Anemia & 41 & 76.0 \\
& Cerebrovascular Disease & 4 & 7.4 \\
& Cancer & 2 & 3.7 \\
& Urinary tract infection & 3 & 5.6 \\
& Chronic obstructive pulmonary disease & 5 & 9.2 \\
& Liver Function disorder & 3 & 5.6 \\
\hline
\end{tabular}

was that our patients had to buy instruments, hemodialyzer and other drugs from market as the same were not available in hospital during the study period.

In Iran the annual cost of dialysis is similar to other developing countries but significantly less than the cost in developed countries. Cost of each session of hemodialysis in Iran was US 74 dollars.

Lai reported in a study that age, gender, DM,CVS disease are risk factors for hemodialysis outcome and cost.

True differences in cost can be as a result of various factors including different management protocols, age, other comorbidities like diabetes mellitus, hypertension obstructive uropathy, urinary tract infection, pregnancy etc. ${ }^{8}$ Other factors can be labor costs and cost of drugs etc. Chang used Anderson model to analyze the predisposing factors enabling and need factors of 2385 patients who continued hemodialysis treatment for over 2 years. The results showed that age gender, diabetes, cardiovascular disease, decreased albumin, urbanization are associated with significant differences in predicting the health expenditure for the following year and female patients utilize more health resources than males. ${ }^{6}$ Most studies reported diabetes as one of the most effective predictive of the cost of medical expenditure for dialysis. 
Arora reported that female patients tend to have more physician visits high out patient expenditure and length of stay than males. ${ }^{10}$ However, our study revealed more utilization of hemodialysis services by male gender in the percentage of $51 \%$.

Tabish SA, Ajaz Mustafa and Rangrez RA in a study conducted in a tertiary care hospital in India reported $61.48 \%$ cost on salary, $12.81 \%$ on drugs and $18.67 \%$ on other activities of total budget. ${ }^{11}$ Our study revealed $20.84 \%$ cost on salary, $12.84 \%$ cost on drugs, $32.50 \%$ cost on instruments and $18.20 \%$ on building rental. Principal expenses born by hospital were in the percentage of $43.89 \%$ on salary and $38.31 \%$ on account of building rental.

\section{Limitation}

The shortcomings of this study are that Values for overhead costs may not have fully reflected the true overhead cost. A subjective bias may have existed. Secondly labeled prices are not generally charged from patients and these patients get discounts on labeled prices because of the rapo developed with chemists because of chronicity of disease.

Despite these shortcomings we believe that the results of our analysis give a good indication of the magnitude of true cost.

\section{Conclusion}

Results of this study could enable health policy makers to design a fair and more convincible reimbursement system for dialysis procedures in future.

Change in dialysis delivery could lead to a more efficient resources utilization. Since the cost of Peritoneal Dialysis is lower, from the public health care providers view, either more patients could be treated with in a fixed budget or the same number of patients could be treated at a lower cost.

In our single centre study, we found that the annual cost of dialysis is comparable to other states of India and cheaper than other SAARC countries. Approaches to reduce cost further are needed by:-

1) Reduce number of ESRD patients by preventing progression to Chronic Kidney Disease by timely and appropriate treatment of Diabetes, Hypertension, Glomerulo nephritis, obstructive Nephropathy, UTI , Vasculitis and pregnancy.

2) Continuous Peritoneal Dialysis can be utilized as a cost reduction measure in selected group of patients.

3) Kidney transplant is most cost effective treatment mode for ESRD.

4) Hemodialysis can reduce transportation charges and is better option in certain patients. This will also reduce Work days lost on treatment.

5) Insurance reimbursements is an option to meet out cost of treatment, this will help both patient and hospital in a longway especially kidney transplant.

Satellite units, free standing centers and charitable NGO owned hemodialysis centres can in a long way prove as cost reduction options.

\section{References}

1. Khana Umesh. Economics of dialysis in India. Indian Journal of Nephrology 2008;(9)19:1-4.

2. Agarwal SK, Dash SC, Irsghad M, Rayu S pandey, RM Singh R. Prevalence of CRF in adults in Delhi India. Neph Dial Transplant 2005;20:1638-42.

3. Modi GK, Jha V. The incidence of end stage renal disease in India: a population based study. Kidney Int 2006;70: 2131-33 PubMed.

4. V Jha. Current status of ESRD care in south Asia. Ethnicity and Disease vol 19Spring 2009.

5. Arefzadeh A, Lessan Pezeshki M, Saifis. Cost of Dialysis in Iran. Saudi Journal Kidney Disease Transplant 2009;20: 307-11.

6. Chang PY. Exploring the risk factors for end stage renal disease dialysis patients and their medical expenses; thesis unpublished Koahsiung Medical University 2001.

7. Lai MS. The current financial status and crisis of the national health insurance. Taiwan Med Journal 2000;43: 37-8.

8. Bin Guang, Kai Li, Tsai Shu, Hsig Yeh, et al. Risk factors and cost analysis for dialysis patients in Taiwan. Health Services Management Research 2010;23:84-93.

9. Chang CT. Factors affecting the consumption of medical resources for routine dialysis patients. Health Care Adm Jour Taiwan 2005;6:291-308.

10. Arora P, Kaustz AT, Obrador GT, Rutherzen R, Han K, Lamers LM. Risk adjusted catialbaes I on the diagnostic cost group model: an empirical evaluation with health survey information. Health Service Res 1999;33:1727-44.

11. Tabish SA, Ajaz Mustafa, Rangrez RA. Hospital accounting based cost studies. Indian experience. JAHA (2001012001-06) vol. 13 No 1.

12. Yashpal Sharma, RK Sharma, PC Chaubey. Costing of inpatient services at a super specialty hospital in India. $J K$ Science 2002;4(4):194-98. 